\title{
EFFECT OF THICKNESS, DENSITY AND CAVITY DEPTH ON THE SOUND ABSORPTION PROPERTIES OF WOOL BOARDS
}

\author{
Hua Qui, Yang Enhui
}

Key Laboratory of Eco-textiles, Ministry of Education, Jiangnan University, Jiangsu, China

\begin{abstract}
:
A novel wool absorption board was prepared by using a traditional non-woven technique with coarse wools as the main raw material mixed with heat binding fibers. By using the transfer-function method and standing wave tube method, the sound absorption properties of wool boards in a frequency range of 250-6300 Hz were studied by changing the thickness, density, and cavity depth. Results indicated that wool boards exhibited excellent sound absorption properties, which at high frequencies were better than that at low frequencies. With increasing thickness, the sound absorption coefficients of wool boards increased at low frequencies and fluctuated at high frequencies. However, the sound absorption coefficients changed insignificantly and then improved at high frequencies with increasing density. With increasing cavity depth, the sound absorption coefficients of wool boards increased significantly at low frequencies and decreased slightly at high frequencies.
\end{abstract}

\section{Keywords:}

wool boards; sound absorption coefficients; thickness; density; cavity depth

\section{Introduction}

The booming development of industrial production, transportation and poor urban planning cause noise pollution to our society, which has become one of the four major environmental hazards including air pollution, water pollution, and solid waste pollution. As it interferes significantly with normal life, especially in people's health, such as causing hearing loss, high stress levels and so on. The use of soundabsorbing materials to control noise is the most effective way to decrease interior noise in the construction industry.

Some research has been conducted to develop sound-absorbing materials, which can be classified either as inorganic or organic materials. Inorganic fibrous porous sound-absorbing materials, such as glass wool, slag wool, rock wool, and aluminum silicate wool, are the traditionally used porous sound-absorbing materials. However, such materials have many disadvantages, as they are easy to break up, produce solid waste and are difficult to degrade, which causes environmental problems. Given the growing awareness of environmental protection, these materials are significantly unsuitable for interior use. ${ }^{[1]}$ Organic sound-absorbing materials and novel inorganic soundabsorbing materials (e.g., activated carbon fiber felts) have recently attracted increasing attention because of their low cost and renewable nature characteristics. The recent advances in the use of these materials have been reviewed by several authors. Tea-leaf-fiber (TLF) is a waste product of tea-leave processing, which is recovered after the drying and chopping of tea leaves. In addition to being a sanitary material, TLF is a product of renewable bio-resources. ${ }^{[2]}$ The sound absorption coefficients of realistic multilayer coconut fibers are affected by micro-perforated facing and airspaces. The airspace layer increases the sound absorption in low-frequency range. Micro- perforated facing promotes sound absorption coefficients in lowfrequency range, but has a reverse effect in the high-frequency region. ${ }^{[3]}$ Discarded polyester fiber and fabric can be reused to produce multilayer structural sound absorption material, which is lightweight, has a simple manufacturing process and wide sound absorption bandwidth with low cost. ${ }^{[4]}$ Needle-punched fabrics that are used for vehicle headliners include two polyester fabrics made of hollow polyester fibers or solid polyester fibers and two polypropylene-composite cellulose fabrics made of jute fibers or kenaf fibers. Hollow polyester fiber fabric has the highest sound absorption and highest loss factor, followed by jute fiber fabric..$^{[5]}$ The acoustic properties of seven activated carbon fiber felts with different specifications are affected by structural factors such as thickness, bulk density, and fiber diameter ${ }^{[6]}$ The acoustic principle of both inorganic or organic absorption materials is similar. ${ }^{[7]}$ Given that the acoustic waves propagating in the porous material cause viscous flow loss, the relative movement between molecules in the material causes friction and converts sound energy into heat energy loss. Thus, sound absorption effects are achieved. ${ }^{[8]}$

In recent years, with the development of science and technology, a novel wool sound-absorbing material made of scraps from woolen mill with fire retardant properties has obtained increasing attention because of its superior sound absorption performance. Coarse wool, which is made of scraps from woolen mill, is used as the main raw material for wool sound-absorbing materials at an average fiber diameter greater than $50 \mu \mathrm{m}$. These coarse wool fibers are unsuitable for spinning and clothing. Thus, the prices of these fibers are low for recycling. Wool sound-absorbing materials that use coarse wool fibers can be added with jute, polyester, and other fibers according to the actual need. No chemical reaction occurs during the production process of wool materials. Moreover, 
this process does not produce hazardous substances that affect the environment, such as waste gas, wastewater and waste residue. Furthermore, the entire production process requires only low energy consumption and does not pollute the environment, as wool materials do not release formaldehyde and other toxic gases. Finally, these materials will neither break and chalk, nor cause itching and allergies when they come in contact with human skin. ${ }^{[9]}$ Thus, this material can be considered for sound absorption, heat insulation and decorative purposes.

Research on the use of wool in sound-absorbing product is scarce. Wool may be used in certain applications as an alternative for man-made mineral fibers and can be promoted as a porous material. ${ }^{[10]}$ Wool products with sound absorption and thermal insulation properties are newly developed green building materials. This product has attracted increasing attention because of its superior sound absorption and thermal and environmental properties. ${ }^{[11]}$ Studies should be conducted on these byproducts to understand the effect of process variables during product manufacturing on sound absorption properties of products.

Given that the wool sound-absorbing building product is widely used in the construction and decoration industries, studying its sound absorption properties is extremely meaningful. This research used wool board as the test material, focused on its preparation, and explored the effects of thickness, density, and cavity depth on sound absorption properties. In this paper, the basics of a theory that develops new types of wool boards with better performance were supported by changing different parameters that will achieve better sound absorption properties of wool boards. Furthermore, studies on wool boards will help achieve a reasonable recycling of waste resources, reduce production and processing costs, as well as help in preventing environmental pollution during the process of production and use.

\section{Materials and Methods}

\subsection{Preparation}

\subsubsection{Raw materials}

In this study, coarse wool used as the main raw material was transformed into wool boards, which makes the best use of the waste. Normally, coarse wool that the scrap formed in the

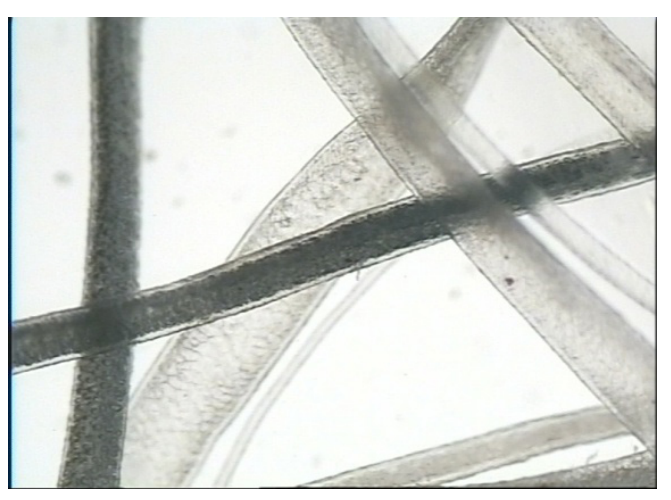

(a) process of wool carding at wool spinning factories is dumped on landfills or it is burned down.

The morphologies of coarse wool fibers were observed by a CU-6 fineness analyzer as shown in Figure 1.

Coarse wool not only has a scale-coated outer layer and cortical layer composed of the wool entity but also has a medulla layer that is opaque in the center of the hair shaft (Figure 1). The medulla layer only exists in coarse wool and not in fine wool. Given the presence of the medulla layer, coarse wool has low strength, elasticity, and elongation and is difficult to dye. Therefore, this material has a low spinning value. The use of coarse wool as the main raw material for building achieves the reasonable utilization of resources.

\subsubsection{Preparation technology of wool boards}

Wool boards belong to the category of non-woven fabrics, and the preparation technology of wool boards is substantially similar to non-woven materials. Discarded wool is a nature fiber. However, such wool is considered scrap that contains many impurities. Thus, impurities were initially filtered out first. Thereafter, by using the combing, sorting, and opening processes, fiber blocks were pressed in the fiber package through a certain mechanical striking and tearing to break the fibers into small fiber bundles. Wool fibers were then thoroughly mixed with heat binding fibers and anti-moth agents. The processing temperature was 110 ${ }^{\circ} \mathrm{C}$. To improve the fireproof performance of the materials, fire retardant finishing was used. Following the further opening of raw materials, fibers were combed into a network and the net body was laid layer by layer to form a multilayer network body (Figure 2). Finally, processes including reinforcement, flatting, length cutting, and transection were conducted to create the wool boards. Without a high-temperature process, it had short process flow and low power consumption. Figure 3 shows the wool boards after complete production.

\subsection{Experiment}

\subsubsection{Materials}

The seven wool boards used in this study were made in Jiangsu KPS Wool Timbering Science Technology Co., Ltd. The wool boards were cut into circles with diameters of 100 and $30 \mathrm{~mm}$.

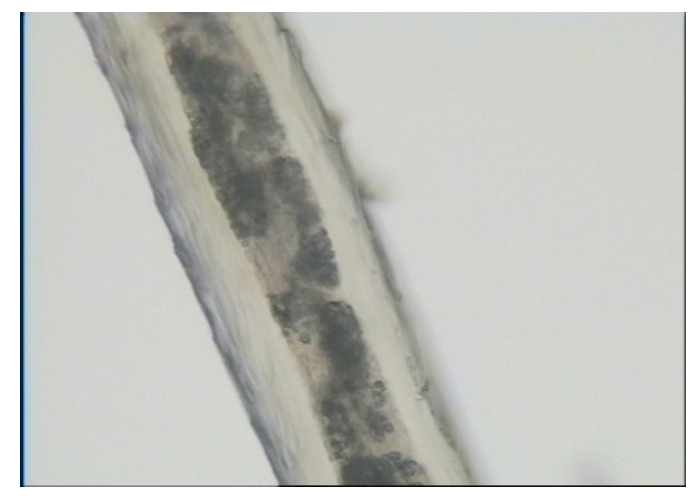

(b)

Figure 1. Coarse wool fibers: (a) x200, (b) x1000. 


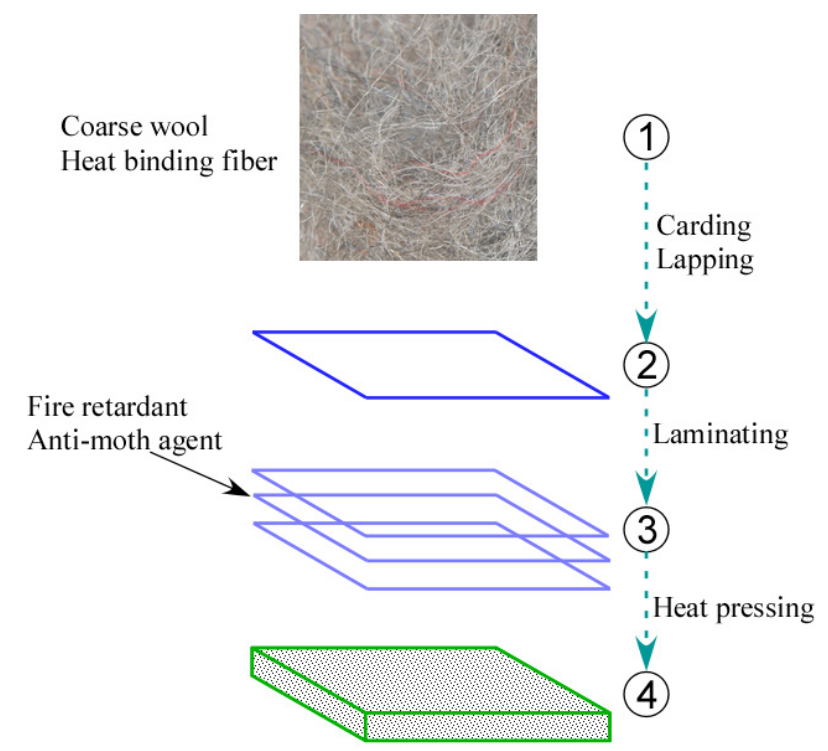

Figure 2. Production flow of wool boards.

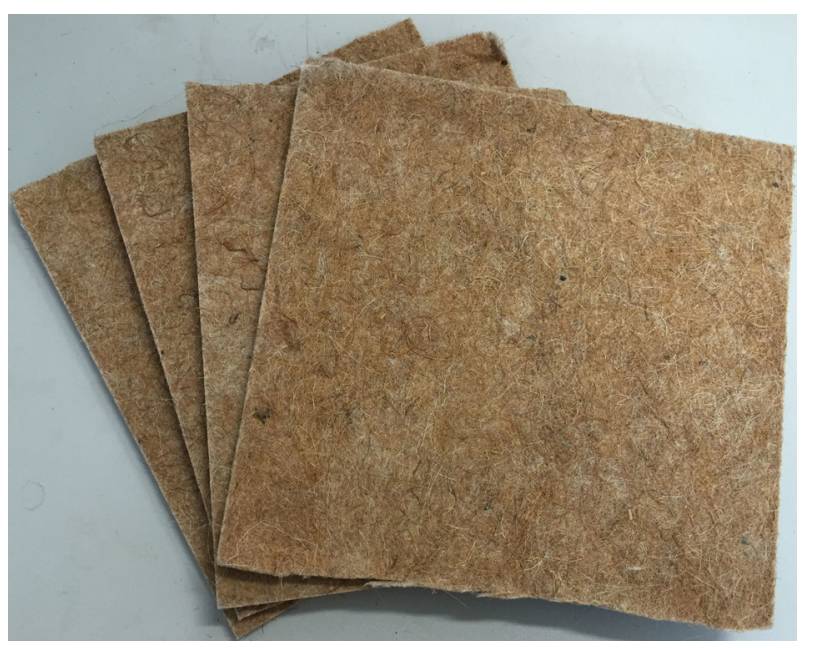

Figure 3. Photo of wool boards.

The basic parameters of the seven wool boards are shown in Table 1.

\subsubsection{Equipment}

By using the transfer-function method stipulated by DIN EN ISO 10534-2-2001 (Acoustics-Determination of Sound
Absorption Coefficient and Impedance in Impedance Tubes Part 2: Transfer-function method) $)^{[12]}$ and two microphone impedance testing systems provided by BSWA Technology Co., Ltd. (China), the testing of sound absorption properties was conducted to measure the sound absorption coefficients in the range of $250-6300 \mathrm{~Hz}$ frequencies.

The whole testing system composed of a computer equipped with software VA-Lab4, an amplifier PA50, a data collector MC3622, and two aluminum alloy impedance tubes SW422 and SW477 (inner diameters of 100 and $30 \mathrm{~mm}$, respectively) with a speaker inside. Furthermore, two microphones of MPA416 that were sensitive in the range of $60-1800 \mathrm{~Hz}$ and $1600-6300$ $\mathrm{Hz}$ were used. The testing system is shown in Figure 4.

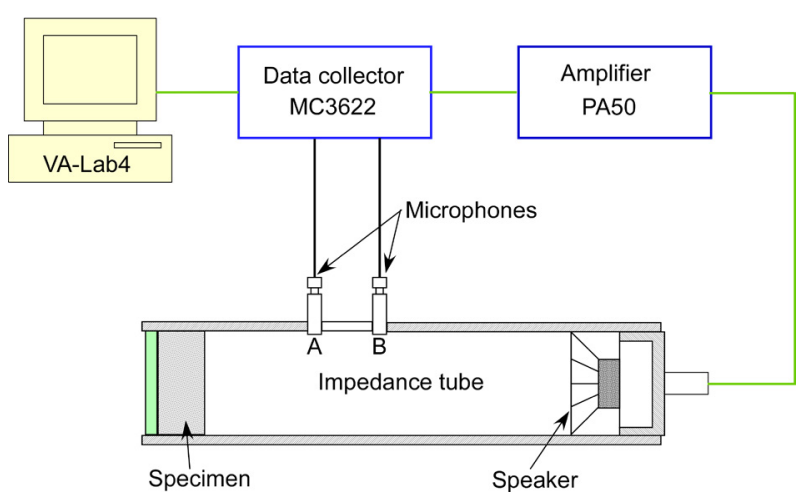

Figure 4. Dual-microphone impedance tube testing system.

\subsubsection{Sound absorption measurement}

Each wool board, with two different specifications, was separately considered for testing five times in the impedance tubes SW422 and SW477. The test sample was placed at one end near the tailgate and fixed during each test. Furthermore, microphones $A$ and $B$ were positioned according to the standard layout. The experiment was then triggered at software VA-Lab4. When the signals of the two microphones stabilized, the test was stopped. After switching the position of the two microphones $A$ and $B$, the test was again triggered. Software VA-Lab4 helped calculate the integration data of sound absorption coefficient for each frequency after completing the test. After deriving the coefficients of $1 / 3$-octave frequencies, the following experiment was conducted.

Table 1. Basic parameters of the seven wool boards used in the experiment

\begin{tabular}{|c|c|c|}
\hline Sample & Thickness $\mathbf{( m m )}$ & Volume density $\left.\mathbf{( k g} / \mathbf{m}^{\mathbf{3}}\right)$ \\
\hline 1 & 6 & 199.50 \\
\hline 2 & 6 & 207.60 \\
\hline 3 & 6 & 249.54 \\
\hline 4 & 6 & 257.54 \\
\hline 5 (gluing two No.3 samples) & 12 & 249.54 \\
\hline 6 (gluing three No.3 samples) & 18 & 249.54 \\
\hline 7 (gluing four No.3 samples) & 24 & 249.54 \\
\hline
\end{tabular}


The average values of the sound absorption coefficients can be calculated from the following equation:

$$
\bar{\alpha}=\frac{\int_{F 1}^{F 2} \alpha(f) d f}{F 2-F 1}
$$

Here, $F_{1}$ is the lower bound of the sound frequency in testing and $F_{2}$ is the upper bound of the sound frequency in testing.

\section{Results and discussion}

\subsection{Effect of thickness}

To study the relation between the sound absorption properties and thickness of wool boards, Sample Nos. 3, 5, 6, and 7 were selected as test materials. Under similar conditions of density $\left(249.54 \mathrm{~kg} / \mathrm{m}^{3}\right)$ and cavity depth $(0 \mathrm{~mm})$ with thicknesses of $6,12,18$, and $24 \mathrm{~mm}$ as variables, the sound absorption coefficients under different frequencies are shown in Figure 5.

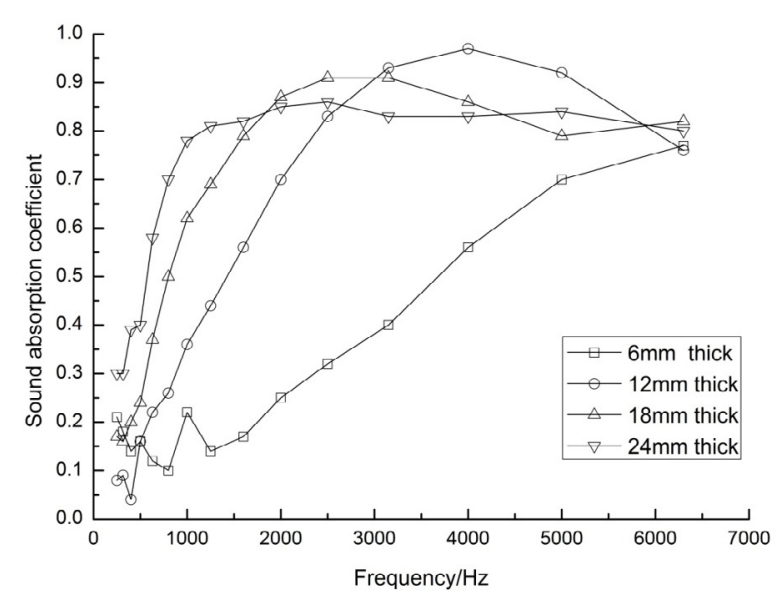

Figure 5. Sound absorption coefficients with different thicknesses of wool boards.

When the thickness was merely $12 \mathrm{~mm}$, the sound absorption coefficients of more than $630 \mathrm{~Hz}$ were at least 0.2 . This result indicated that wool boards at low and middle frequencies had excellent sound absorption properties.

With increasing frequency, wool boards with thicknesses of $6 \mathrm{~mm}$ displayed increasing sound absorption coefficient with a range of $250-6300 \mathrm{~Hz}$. This result can be attributed to the following factor: when the thickness of the board is not too thick, the higher the frequency of incident acoustic wave is, the greater is the degree of fiber activation. The air vibration between fibers accelerates the interaction of the edge of pores and the air. Thus, a great viscous force is formed. Hence, a large amount of sound energy attenuates and converts into heat. Thereafter, the heat conducts rapidly between the pores of the fibers. Therefore, the sound absorption properties of the board in high frequencies are better than in low frequencies. Moreover, when the thickness exceeded $6 \mathrm{~mm}$, the sound absorption coefficients increased sharply in the low frequencies and fluctuated in varying degrees in high frequencies. This phenomenon is caused by the absorption of low-frequency acoustic waves in the internal board because of the large thickness of the board. This finding is in line with the principle above. Therefore, the sound absorption coefficients in low frequencies increase with increasing frequency. Acoustic waves in high frequencies are absorbed primarily at the surface of the board. Sound energy, which can be absorbed by the surface of the board, is limited and less energy enters the interior. Thus, fluctuations occur in sound absorption coefficients with increasing high frequency, in which sound absorption peak can be observed.

Two phenomena can be observed from the longitudinal comparison of four curves. At a specific frequency of the low frequencies' range, sound absorption coefficient increases with increasing thickness. This result is mainly due to the absorption of acoustic waves within the board at low frequencies. Under similar conditions of density and other factors, pore channels increase in length with increasing thickness, thus allowing acoustic waves to pass through and to be blocked easily by tortuous passages with increasing thickness. Thus, sound energy loss is more since the acoustic waves propagate in the pore. Hence, the sound absorption coefficients will also increase. While the specific frequency is in the high-frequency range, the sound absorption coefficient insignificantly changes with increasing thickness when the thickness is over $6 \mathrm{~mm}$. This result is also caused by the absorbed high-frequency acoustic waves in the surface of the board.

In general, the sound absorption coefficients of wool boards can be improved at the low-frequency range by increasing the thickness. However, this approach has an insignificant effect at high frequencies. Thus, increasing the thickness of wool boards will insignificantly increase sound absorption coefficients when the boards meet the requirement of sound absorption coefficients at low frequencies.

\subsection{Effect of density}

Samples Nos. 1, 2, 3, and 4 were selected as test materials to determine the relationship between the sound absorption properties and density of wool boards. Under similar conditions of thickness $(6 \mathrm{~mm})$ and cavity depth $(0 \mathrm{~mm})$ with densities of $199.50,207.60,249.54$, and $257.54 \mathrm{~kg} / \mathrm{m}^{3}$ as variables, the sound absorption coefficients under different frequencies are shown in Figure 6.

With increasing density, the sound absorption coefficients of wool boards fluctuated or slightly increased with increasing frequency in the low frequencies' range. Furthermore, in the range of high frequencies, the sound absorption coefficients showed a significant increasing trend (Figure 6). This result is because large density creates small pores in the interior board. Entering the interior is difficult for low-frequency acoustic waves and a large part of these waves are reflected at the surface, which leads to the poor sound absorption properties of the board in low frequencies. Meanwhile, with increasing density, the permeability of the board deteriorates and flow resistance 


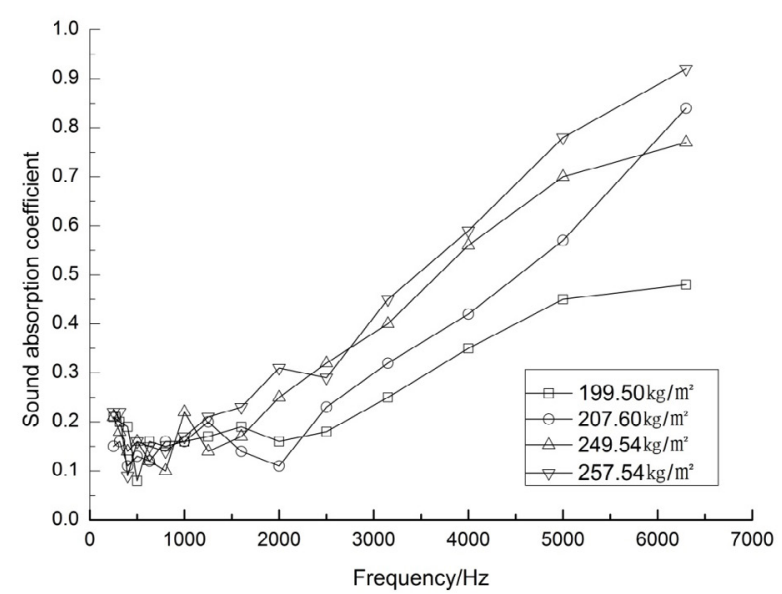

Figure 6. Sound absorption coefficients with different densities of wool boards.

becomes larger. Given the absorbed high-frequency acoustic waves in the board surface, with intensifying flow resistance, the greater acoustic waves attenuate at the surface, the greater the degree of being absorbed, which leads to better sound absorption properties of high-frequency acoustic waves with increasing density. However, the influence of increasing density on the effect of high-frequency acoustic waves is insignificant, similar to that of thickness in degree.

Thus, increasing density insignificantly enhanced the sound absorption coefficients at low frequencies. After a great degree of compression in the process of producing and processing of wool boards, acoustic advantages as a porous material cannot fully play its role, such as small flow resistance and high porosity, which leads to poor sound absorption properties in low frequencies and high frequencies. Based on the result, increasing density insignificantly improves sound absorption properties of wool boards.

\subsection{Effect of cavity depth}

To study the relation between sound absorption properties and cavity depth of wool boards, we selected No. 3 samples as test materials. Under similar condition of density $(249.54 \mathrm{~kg} /$ $\left.\mathrm{m}^{3}\right)$ and thickness $(6 \mathrm{~mm})$ with cavity depths of $0,6,12$, and 18 $\mathrm{mm}$ as variables, sound absorption coefficients under different frequencies are shown in Figure 7.

Under a particular cavity depth, low-frequency sound absorption coefficients of wool boards increased with increasing frequency. Moreover, a peak was observed while sound absorption coefficients at high frequencies decline in varying degrees (Figure 7). The reason behind the appearance of a peak and the varying of sound absorption coefficients in high frequencies is when the cavity depth of the back of board (one side near the tailgate) is equal to the odd times of $1 / 4$ wavelength, the maximum sound absorption coefficient can be obtained at its corresponding frequency. The place that has odd multiples of $1 / 4$ wavelength to the tailgate is a peak, and the sound pressure is zero. However, air particles have the maximum vibration velocity and sound energy loss of the board from

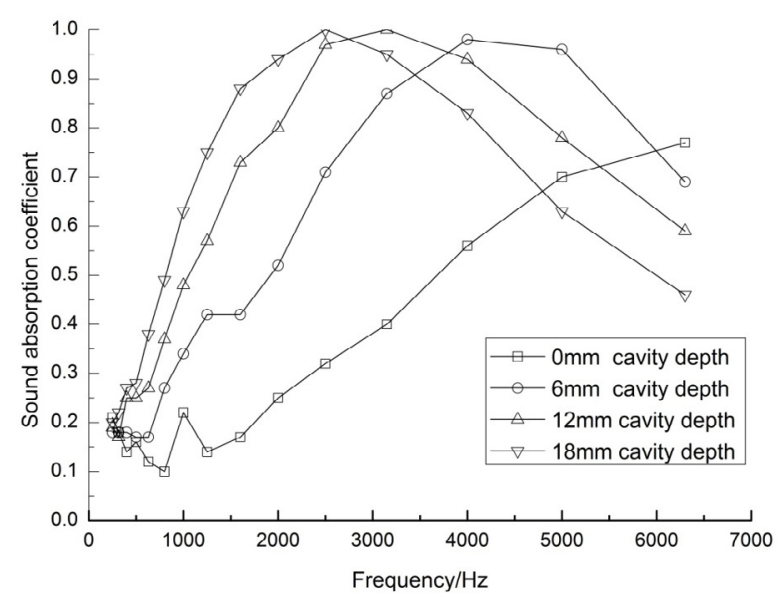

Figure 7. Sound absorption coefficients with different cavity depths of wool boards.

friction damping is also the largest, causing the greatest sound absorption effect on the board. The peak is shown in Figure 7. $1 / 2$ wavelength away from the tailgate is an integral multiple of $1 / 2$ wavelength, sound pressure being maximum, and vibration velocity of air particles being zero; thus, the sound absorption coefficient of the board reaches minimum at the corresponding frequency. Figure 7 shows that sound absorption properties reduce at high frequencies.

Longitudinal comparison of four curves indicates that at a particular frequency, increasing the depth of cavity can significantly improve sound absorption properties of wool boards in low frequencies. This result is because of the presence of the cavity. Acoustic waves transmit through and touch the rigid tailgate (reality is the wall); between the back of the board and the tailgate, reflection occurs repeatedly, which is equivalent to increasing the effective thickness of the board, to improve its low-frequency sound absorption properties. Meanwhile, at high frequencies, the frequencies are closer to the valley because of increasing cavity depth. Thus, the sound absorption properties of the board decrease. Therefore, improving sound absorption properties of wool boards at low frequencies by increasing cavity depth is more economic and reasonable than increasing the thickness of boards. According to this principle, by adjusting the cavity depth between the back and the wall of boards, the design needs of the sound absorption properties will be achieved.

\section{Conclusions}

As a new type of porous sound-absorbing material, wool board has been widely used in various fields, such as decoration and environmental friendly properties, with its excellent sound absorption and insulation. Thus, this material has a great potential market. Studying the sound absorption property, which is the most important characteristic of wool boards, has guiding and referring significance to the design and application of the material. This paper explored the effects of thickness, density, and cavity depth on sound absorption properties of wool boards. Based on the results, the following conclusions can be drawn: 
(1) In the range of $250-6300 \mathrm{~Hz}$, wool boards have better sound absorption performance at high frequencies than that at low frequencies. When the thickness of the board is $6 \mathrm{~mm}$, sound absorption coefficients increase with increasing frequency. After the thickness reaches $12 \mathrm{~mm}$, the sound absorption coefficient increases at low frequencies. After reaching the peak, the sound absorption coefficient fluctuates with increasing frequency. By increasing the thickness of the board, sound absorption performance at low frequencies changes for the better. However, such method has insignificant effect on the sound absorption performance at high frequencies.

(2) Increasing density insignificantly improves the sound absorption properties of wool boards. Thus, this method is not suggested. In particular, such method has insignificant influence on improving the low-frequency sound absorption coefficients.

(3) Increasing the cavity depth can effectively enhance the low-frequency sound absorption coefficients of wool boards. Although the effect at high frequencies is slightly low, this method is still a reasonable and economic method to improve sound absorption properties of wool boards.

\section{Acknowledgements}

The authors are grateful for the financial supported by Prospective Industry-university-research Project of Jiangsu Province (BY2016022-14) and the Fundamental Research Funds for the Central Universities (No. JUSRP51301A and JUSRP51417B).

\section{References}

[1] Y. C. Kang. Design and technology of practical building absorption. (2007)1th ed. Beijing: China Build Ind Press.
[2] S. Ersoy, H. Küçük. (2009). Investigation of industrial tealeaf-fiber waste material for its sound absorption properties. Appl Acoust, 70(1), 215-220.

[3] M. J. M. Nor, N. Jamaludin, F. M. Tamiri. (2004). A preliminary study of sound absorption using multi-layer coconut coir fibers. Tech Acoust, 3, 1-8.

[4] X. Yu, L. Lv, C. Wei, Y. Cui, X. Wang, T. Li. (2014). Research on sound absorption properties of multilayer structural material based on discarded polyester fiber. $J$ Text Inst, 105(10), 1009-1013.

[5] Y. Na, G. Cho. (2010). Sound absorption and viscoelastic property of acoustical automotive nonwovens and their plasma treatment. Fiber Polym, 11(5), 782-789.

[6] Y. Shen, G. Jiang. (2014). Effects of different parameters on acoustic properties of activated carbon fiber felts. J Text Inst, 105(4), 392-397.

[7] Rwawiire S, Tomkova B, Gliscinska E. (2015). Investigation of Sound Absorption Properties of Bark Cloth Nonwoven Fabric and Composites. Autex Research Journal, 15(3):173-180.

[8] D. Y. Ma, H. Shen. Handbook of Acoustics. 2th ed. Beijing (2004): Sci Press.

[9] Arenas C, Leiva C, Vilches L F. (2017). Approaching a methodology for the development of a multilayer sound absorbing device recycling coal bottom ash. Applied Acoustics, 115(1):81-87.

[10] K. O. Ballagh. (1996). Acoustical properties of wool. Appl Acoust, 48(2), 101-120.

[11] G. Cheng. (2009). Properties and application of wool thermal insulating products for sound absorption. New Build Mater, 36(5), 63-66.

[12] DE-DIN. DIN EN ISO 10534-2-2001, (2001) (AcousticsDetermination of sound absorption coefficient and impedance in impedance tubes-Part 2: Transfer function method). Germany. 